\title{
Latent habituation of the orienting response in the preweanling rat
}

\author{
RICK RICHARDSON and BYRON A. CAMPBELL \\ Princeton University, Princeton, New Jersey
}

\begin{abstract}
The effect of inhibiting the orienting response on information processing was examined in four experiments. A nonsignal auditory stimulus was presented four times to preweanling rats either 30 sec or 15 min after they had been placed in an unfamiliar environment (Experiments $1 \mathrm{~A}$ and 2), shocked (Experiment 1B), or experienced a shift in environmental context (Experiment 1C). Both an autonomic (heart rate) and a behavioral component of the orienting response to the novel stimulus were recorded. In the 15-min condition, the auditory stimulus elicited a consistent orienting response on the first trial that habituated rapidly with successive trials. In contrast, the auditory stimulus did not elicit a detectable orienting response in the 30-sec condition on any of the four trials. However, when the auditory stimulus was re-presented after a brief retention interval, a comparable level of habituation was seen in both groups. These results demonstrate that animals in the 30-sec condition detected, attended to, and encoded the auditory stimulus even though they did not orient, either autonomically or behaviorally, to that stimulus when it was first presented. This process of response-independent habituation is best described as latent habituation. Like latent learning, latent habituation took place in the absence of any observable change in behavior. The implications of this effect for current theories of habituation and of the orienting response are discussed.
\end{abstract}

Habituation of unconditioned reactions to sensory stimuli has been a powerful tool for studying nonassociative learning in animals ranging from Aplysia to humans (e.g., Bornstein, 1985; Carew, 1984). The relatively simple procedures used to study habituation have made this technique especially popular in animal and developmental research. Habituation of the gill-withdrawal response in Aplysia, for example, has dominated work on the cellular bases of learning and memory, whereas habituation of visual fixations on a novel stimulus pattern has been the most frequently used technique to assess learning and memory in the human infant. For the last several years, we have been using habituation of the orienting response to novel sensory stimuli to assess nonassociative learning and memory in the developing rat (e.g., Richardson, Hayne, \& Campbell, 1992a).

The orienting response is an unconditioned reaction to novel stimuli of low to moderate intensity that consists of a variety of central, autonomic, and behavioral responses (e.g., Turpin, 1983). The specific autonomic response recorded in our research is heart rate, which decreases in response to novel olfactory, visual, and auditory stimuli (e.g., Siegel, Sananes, Gaddy, \& Campbell, 1987). The behavioral component of the orienting re-

This research was supported by National Institute of Mental Health Grant MH01562 and National Institute on Alcohol Abuse and Alcoholism Grant AA07641 to B.A.C. The authors would like to thank Harlene Hayne and Pamela $S$. Hunt for their helpful comments on earlier versions of this manuscript. Reprint requests should be addressed to B. A. Campbell, Department of Psychology, Princeton University, Princeton, NJ 08544-1010. sponse is stimulus specific: olfactory stimuli elicit sniffing, visual stimuli elicit rearing, and auditory stimuli elicit a ballistic jerk of the head (Siegel et al., 1987). The orienting response has a number of characteristics that make it an especially promising measure for studying nonassociative learning and memory. First, the orienting response is a ubiquitous reaction that occurs across ontogeny and phylogeny (e.g., Campbell, Hayne, \& Richardson, 1992). Being able to compare the same response across ages, or across species, should expedite both empirical and theoretical analyses. Second, the orienting response is a very robust phenomenon. Presentation of a novel auditory stimulus to a preweanling rat, for example, decreases heart rate by about 40 beats per minute and produces a head jerk approximately $70 \%$ of the time (e.g., Richardson, Siegel, \& Campbell, 1988). Finally, the orienting response habituates relatively rapidly (e.g., Graham, 1979). In the rat, the cardiac component of the orienting response to a novel auditory stimulus typically habituates in fewer than five trials (e.g., Richardson, Hayne, \& Campbell, 1992b).

The focus of this paper is on what we have recently described as "latent habituation" of the orienting response (Richardson et al., 1992b). In that study, we found that the cardiac orienting response in preweanling rats to an uninterrupted, 60 -sec auditory stimulus did not habituate. Onset of the stimulus elicited a decrease in heart rate that, instead of habituating, persisted for the entire $60-\mathrm{sec}$ period. In contrast, when the $60 \mathrm{sec}$ of auditory stimulation was presented in six temporally spaced 10-sec blocks, habituation occurred rapidly, with the stimulus ceasing to elicit a change in heart rate by about the fourth trial. 
However, when the same auditory stimulus was presented again following a 15-min retention interval, the cardiac orienting response was not elicited in either group. This suggests that habituation had occurred during the uninterrupted 60-sec stimulus, even though there was no observable decrement in the cardiac component of the orienting response; hence the term latent habituation.

Latent learning is said to occur when animals show no evidence of learning during the initial phase of an experiment, usually in the absence of reinforcement, but then demonstrate that some learning had indeed occurred during a subsequent test session (e.g., Chamizo \& Mackintosh, 1989; Tolman, 1932). In latent habituation, the same process appears to take place. During the initial stage of the experiment, no decrement in responding was observed (i.e., heart rate did not return to baseline), but on a subsequent test the auditory stimulus did not elicit an orienting response, indicating that learning had occurred. The major difference between the two phenomena appears to be that latent learning requires the introduction of a reinforcer during the subsequent test in order for the learning to be expressed, whereas latent habituation does not.

The purpose of the present study was to determine whether latent habituation also occurs when the orienting response to a novel stimulus is inhibited. When an auditory stimulus that normally elicits an orienting response is presented $30 \mathrm{sec}$ after animals have been placed in an unfamiliar environment, shocked, or experienced a shift in contextual cues, no evidence of a cardiac or a behavioral orienting response is detected (Richardson et al., 1988; Saiers, Richardson, \& Campbell, 1990). If the orienting response is a necessary precursor for subsequent stages of information processing (e.g., Ohman, 1979), then inhibition of this response should preclude the formation of a neuronal representation of the eliciting stimulus. From this perspective, presentation of the same stimulus $15 \mathrm{~min}$ later should elicit the standard orienting response, since a central representation of that stimulus was not established. In contrast, if latent habituation occurs in this situation, then presentation of the same auditory stimulus should not elicit an orienting response on the subsequent test.

\section{EXPERIMENT 1}

In the first experiment, unrestrained preweanling rats were given four presentations of a novel auditory stimulus either immediately $(30 \mathrm{sec}$ ) or $15 \mathrm{~min}$ after the animals had been placed in an unfamiliar environment (Experiment 1A), shocked (Experiment 1B), or experienced a shift in environmental context (Experiment 1C). Fifteen minutes after the fourth stimulus presentation, all animals were reexposed to the same stimulus. Both the behavioral and cardiac components of the orienting response were recorded during the initial and subsequent stimulus series.

\section{General Method}

\section{Subjects}

The subjects used in this research were experimentally naive Sprague-Dawley rats bred in the Department of Psychology vivarium at Princeton University and were $17 \pm 1$ days of age at test. Birth was counted as Day 0. Litters were culled to 8 pups on Day 2. No more than 2 animals from any single litter were included in the same group. The subjects were housed in $48 \times 25.5 \times 20.5 \mathrm{~cm}$ polycarbonate rodent cages with their dam and littermates. The wood-chip bedding in these cages was changed weekly. All animals had ad-lib access to food and water and were maintained on a 16:8-h light:dark cycle (lights on at 7:30 a.m.). All testing was done during the light portion of the cycle.

There were several reasons for using only preweanling rats in this study. First, the magnitude of the cardiac component of the orienting response is slightly larger, although usually not significantly so, in animals this age than in older animals. Second, previous research had shown that placement in an unfamiliar environment produced equivalent inhibition of the orienting response in young and adult animals (Richardson et al., 1988). Third, implantation of the subcutaneous ECG electrodes used with adults requires general anesthesia and a 24-h recovery period, whereas the transcutaneous electrodes used in the preweanling rats can be rapidly implanted with minimal distress and without anesthesia. Fourth, the final experiment in this study required loss of habituation over time (forgetting), and since this occurs more rapidly in preweanling rats than in adults, they were a more suitable subject for this phase of the research (Richardson \& Campbell, 1991).

\section{Apparatus}

Testing was performed in a clear Plexiglas chamber $(30 x$ $17.5 \times 46 \mathrm{~cm}$ ) housed inside a single-wall Industrial Acoustics soundattenuating chamber (IAC). Dim illumination was provided by a $15 \mathrm{~W}$ incandescent light bulb located on the rear wall of the IAC. A small window in the door of the IAC permitted observation of the animal. This apparatus was used in all experiments except Experiment $1 \mathrm{C}$, which used a slightly different test chamber. That apparatus is described in the Method section of that experiment.

\section{Sensory Stimulus}

An 80-dB (as measured on Scale $\mathrm{C}$ of a Simpson Sound Level Meter), $1600-\mathrm{Hz}$, pulsating tone was used in this study. The tone was generated by a Coulbourn Instruments precision signal generator, amplified by a Realistic audio amplifier (Model SA-10), and presented by a 4-in. speaker (Jensen) located inside the IAC. The tone was $10 \mathrm{sec}$ in duration and was pulsed at a rate of two per second with a rise-fall time of $250 \mathrm{msec}$.

\section{Heart Rate Recording Procedure}

To record heart rate, two transcutaneous stainless steel electrodes (25 ga., approximately $1.5 \mathrm{~cm}$ in length) shaped like safety pins were used. These electrodes were acutely implanted just prior to test (this took 10-15 sec). The electrodes and attached leads (32ga. Teflon coated, Alpha Wire Co.) did not appreciably interfere with the subjects' behavior. One electrode was placed ventrally, near the urogenital region, and the other was placed dorsally, at the nape of the neck. Cardiac potentials were amplified by a Grass preamplifier (Model P511). The R spike activated a Schmitt trigger (Coulbourn Instruments), which was used to determine the interbeat intervals to the nearest millisecond. An IBM-compatible PC controlled all timing sequences as well as data collection. The cardiac signal was continuously displayed on an oscilloscope (Hitachi Model V-212). 


\section{Treatment of Cardiac Data}

Interbeat intervals were measured, to the nearest millisecond, for all subjects during a 5-sec prestimulus period, as well as during the 10-sec stimulus, on all trials. The interbeat interval data were converted to a beats-per-minute measure for analysis. The auditory stimulus used in this study typically elicits a decrease in heart rate of $40-50$ beats per minute in preweanling rats.

\section{Behavioral Orienting Response}

In addition to decreasing heart rate, novel auditory stimuli also elicit a modality-specific behavioral response that consists of a discrete, ballistic head jerk that is easy to observe and record (Siegel et al., 1987). This response occurs reliably on Trial 1 and habituates very rapidly thereafter. In the present study, the behavioral response was recorded on all trials by a single observer. The interrater reliabilty of this measure was assessed by a separate experiment in which two observers independently scored the behavioral response to a novel auditory stimulus in 50 animals (Richardson $\&$ Wang, 1992). The two observers agreed on $96 \%$ of the observations.

\section{Experiment 1A}

The purpose of the first experiment was to determine if latent habituation occurred when the orienting response was inhibited by placing animals in an unfamiliar environment. A novel auditory stimulus was presented either $30 \mathrm{sec}$ or $15 \mathrm{~min}$ after the animals had been placed in an unfamiliar test environment. On the basis of previous research (Richardson et al., 1988), we predicted that the subjects given only $30 \mathrm{sec}$ to adapt to the environment would not show an orienting response to the stimulus, whereas those given $15 \mathrm{~min}$ to adapt would. Fifteen minutes after the initial stimulus sequence, the same stimulus was re-presented to each group to determine what effect, if any, inhibition of the orienting response had on habituation of the orienting response to the auditory stimulus.

\section{Method}

Two groups $(n s=12)$ of experimentally naive preweanling rats were used as subjects. Each group received four presentations of the auditory stimulus, each separated by $60 \mathrm{sec}$. In one condition, the first stimulus was presented $30 \mathrm{sec}$ after the animal had been placed in the unfamiliar test chamber, whereas in the other condition, the first stimulus was presented $15 \mathrm{~min}$ after placement in the test chamber. The animals in both groups remained in the test chamber following the fourth stimulus. After an additional $15 \mathrm{~min}$ in the chamber, the tone was presented four more times to the animals in each group.

\section{Results}

In all cases where repeated trials were included as a factor in an analysis of variance (ANOVA), the reported probability values were adjusted by the GreenhouseGeisser method.

Heart rate orienting response. The animals given only $30 \mathrm{sec}$ to adapt to the unfamiliar test environment did not show a significant decrease in heart rate on any of the four trials. The subjects allowed to adapt to the unfamiliar environment for $15 \mathrm{~min}$ prior to presentation of the stimulus showed a substantial decrease in heart rate on the first trial that habituated over trials. These data are pre- sented in the left panel of Figure 1. Analysis of these data yielded a significant effect of group, trial, and a group $X$ trial interaction (smallest $F=6.14, p<.01$ ). The group $\times$ trial interaction was due to the significant trial effect for the subjects in the 15 -min condition $[F(3,33)=$ $11.55, p<.01]$ but not for those in the 30 -sec condition $[F(3,33)=1.83, p>.10]$.

On the second series of stimulus presentations, which occurred 15 min after the first, the auditory stimulus did not elicit significant bradycardia in either group. These results are presented in the right panel of Figure 1. Analysis of these data did not yield any significant effects (largest $F=1.99, p>.10$ ). This indicates that both groups habituated to the stimulus during the initial presentation series and retained habituation over the 15-min interval.

To examine the possibility that the auditory stimulus elicited an initial decrease in heart rate in the 30-sec group that was either masked by a subsequent increase in heart rate or obscured by the grouping of data in 10-sec blocks, the response to the first $10-\mathrm{sec}$ stimulus was examined on a second-by-second basis. These data are presented in Figure 2. The auditory stimulus elicited a rapid decrease in heart rate in the group allowed to adapt to the test environment for $15 \mathrm{~min}$, whereas no consistent change in heart rate could be seen in the 30-sec group. The effect of time was significant for the 15-min group ( $p<$ $.01)$ but not for the 30-sec group $(p>.10)$.

Behavioral orienting response. Because the behavioral response to a novel auditory stimulus is most pronounced on the first trial, only data from the first stimulus presentation in each session was examined. The animals that had been in the unfamiliar test environment for only $30 \mathrm{sec}$ prior to presentation of the first auditory stimulus were much less likely to show a behavioral orienting response than were the animals that had been in the test environment for $15 \mathrm{~min}$. Analysis of the percentage of animals

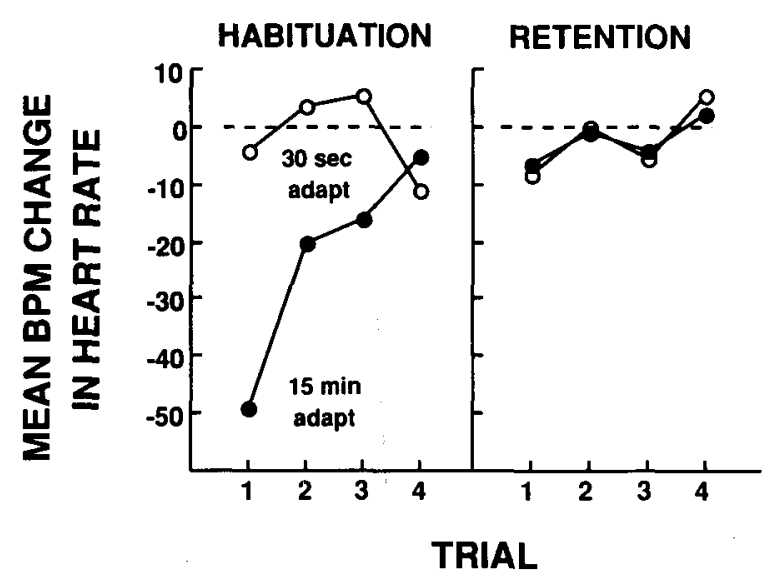

Figure 1. Mean change in heart rate to a 10-sec, nonsignal auditory stimulus in the animals allowed to adapt to the test environment for either $30 \mathrm{sec}$ (open circles) or $15 \mathrm{~min}$ (closed circles) prior to the initial stimulus presentation (left panel). The right panel shows the mean change in heart rate to the same auditory stimulus in these two groups following a 15-min retention interval. 


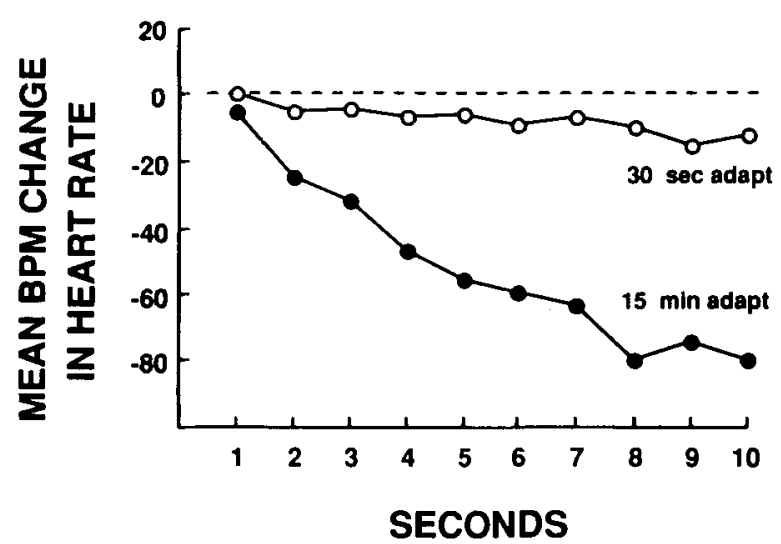

Figure 2. Mean second-by-second change in heart rate to the first presentation of a 10-sec auditory stimulus in the animals allowed to adapt to the test environment for either $30 \mathrm{sec}$ (open circles) or 15 min (filled circles).

Table 1

Percentage of Subjects Exhibiting a Head Jerk to the First Tone Presentation in Experiments 1A and 1B

\begin{tabular}{cccccc} 
& \multicolumn{2}{c}{ Experiment 1A } & & \multicolumn{2}{c}{ Experiment 1B } \\
\cline { 2 - 3 } \cline { 5 - 6 } Adaptation & Habituation & Retention & & Habituation & Retention \\
\cline { 2 - 3 } $30 \mathrm{sec}$ & 0 & 8 & & 42 & 8 \\
$15 \mathrm{~min}$ & 67 & 17 & & 75 & 8 \\
\hline
\end{tabular}

exhibiting this response on the first trial of the first session yielded a significant group difference $\left(\chi^{2}=12, p<\right.$ $.001)$. During the second session, the auditory stimulus did not elicit a consistent behavioral response in either group. These data are presented in Table 1.

Basal heart rates. Analysis of basal heart rates (obtained during the 5-sec prestimulus period) revealed a significant effect of trial and a group $\times$ trial interaction during the first session (smallest $F=5.30, p<.003$ ). The significant group $\times$ trial interaction was due to the slight increase in heart rate across trials for the animals tested after $30 \mathrm{sec}$ of adaptation and a slight decrease in those animals tested after 15 min of adaptation. Pairwise com- parisons with the Tukey test $(p<.05)$ showed that significant differences in basal heart rates occurred only on Trial 4. It is important to note that the two groups did not differ in baseline heart rate on Trial 1 when the maximal differences in the heart rate orienting response were observed. No significant differences in basal heart rate were observed in the second session (largest $F=1.97$, $p>.10$ ). These data are presented in Table 2 .

\section{Discussion}

An auditory stimulus presented to animals following 15 min of adaptation to an unfamiliar test environment elicits an orienting response consisting of a marked decrease in heart rate and a characteristic rapid movement of the head. With repeated stimulus presentations, the orienting response habituates. When that same stimulus is presented $15 \mathrm{~min}$ later, the orienting response is not elicited, thereby demonstrating retention of habituation.

In contrast, the animals do not show an orienting response to the same auditory stimulus when it is presented after just $30 \mathrm{sec}$ of adaptation to the test environment. Although the animals do not orient to the stimulus, either behaviorally or autonomically, they also do not respond to that stimulus when it is presented again 15 min later. This suggests that the orienting response habituated even though the response was not elicited initially. This process of response-independent habituation is best described as latent habituation. Like latent learning, latent habituation took place in the absence of any observable change in behavior.

\section{Experiment 1B}

The same basic paradigm used in the preceding experiment was used again. The only difference was that the four presentations of the auditory stimulus began either $30 \mathrm{sec}$ or $15 \mathrm{~min}$ after the animals had been given a brief series of electric shocks. This procedure had been shown to inhibit the orienting response in an earlier study (Saiers et al., 1990). As in the preceding experiment, all animals were given a second series of stimulus presentations 15 min after the first in order to determine the effects of shock-induced inhibition of the orienting response on habituation.

Table 2

Basal Heart Rate (Beats per Minute) of Subjects in Experiments 1A, 1B, and 1C

\begin{tabular}{|c|c|c|c|c|c|c|c|c|}
\hline \multirow[b]{3}{*}{ Adaptation } & \multicolumn{4}{|c|}{ Habituation } & \multicolumn{4}{|c|}{ Retention } \\
\hline & \multicolumn{4}{|c|}{ Trial } & \multicolumn{4}{|c|}{ Trial } \\
\hline & 1 & 2 & 3 & 4 & 1 & 2 & 3 & 4 \\
\hline \multicolumn{9}{|c|}{ Experiment $1 \mathrm{~A}$} \\
\hline $30 \mathrm{sec}$ & 502 & 516 & 523 & 540 & 521 & 483 & 503 & 500 \\
\hline $15 \mathrm{~min}$ & 527 & 487 & 502 & 508 & 502 & 503 & 502 & 507 \\
\hline \multicolumn{9}{|c|}{ Experiment 1B } \\
\hline $30 \mathrm{sec}$ & 530 & 535 & 530 & 542 & 500 & 493 & 502 & 501 \\
\hline $15 \mathrm{~min}$ & 526 & 510 & 483 & 502 & 493 & 495 & 494 & 474 \\
\hline \multicolumn{9}{|c|}{ Experiment 1C } \\
\hline $30 \mathrm{sec}$ & 473 & 477 & 475 & 495 & 481 & 472 & 469 & 467 \\
\hline $15 \mathrm{~min}$ & 512 & 492 & 497 & 495 & 502 & 489 & 486 & 483 \\
\hline
\end{tabular}




\section{Method}

Two groups $(n s=12)$ of experimentally naive preweanling rats were used as subjects. The animals in both groups received a series of five brief inescapable shocks ( $1 \mathrm{~mA}, 1-\mathrm{sec}$ duration, 5-sec intershock interval) through the same electrodes used to record heart rate. The shocks began following $15 \mathrm{~min}$ of adaptation to the test chamber. Either $30 \mathrm{sec}$ or $15 \mathrm{~min}$ after the last shock, the animals were given four presentations of the auditory stimulus, each separated by $60 \mathrm{sec}$. Following the fourth tone, the animals remained in the test chamber for $15 \mathrm{~min}$. Following this period, the auditory stimulus was presented again to all animals.

\section{Results}

Heart rate orienting response. The animals shocked $30 \mathrm{sec}$ prior to the presentation of the auditory stimulus exhibited markedly smaller cardiac decelerations than did the animals receiving the shock 15 min prior to the first stimulus presentation. These data are presented in the left panel of Figure 3. Analysis of the change in heart rate during the first series of tone presentations yielded a significant effect of group, trial, and a group $\times$ trial interaction [smallest $F(3,66)=8.33, p<.01]$. The interaction between group and trial was due to a significant effect of trial in the animals tested 15 min after shock $[F(3,33)=14.96, p<.01]$ but not in the animals tested $30 \mathrm{sec}$ after shock $(F<1.0)$.

Inhibition of the orienting response by shock, however, did not affect habituation of the orienting response to the auditory stimulus. When the same stimulus was presented 15 min later, neither group displayed a cardiac orienting response. These data are depicted in the right panel of Figure 3. Analysis of these data did not yield any significant effects (largest $F=1.58, p>.10$ ).

Behavioral orienting response. The percentage of animals exhibiting the head-jerk response to the initial presentation of the auditory stimulus is presented in Table 1 . Although the animals shocked $30 \mathrm{sec}$ prior to tone presentation seemed to be less likely to exhibit this response

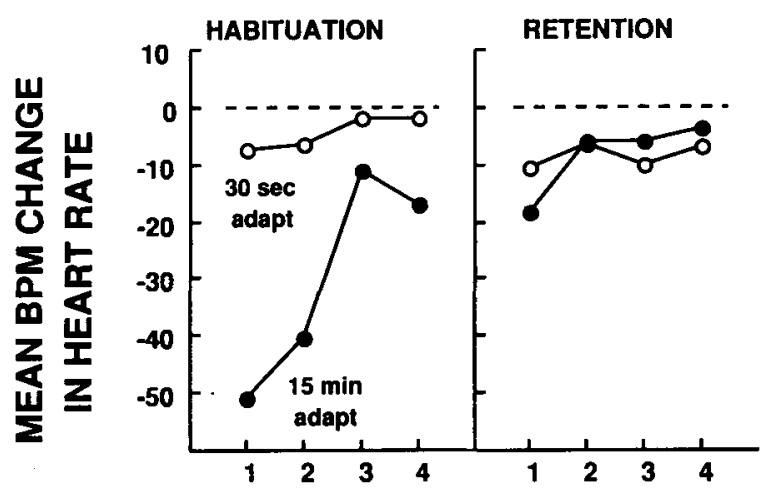

\section{TRIAL}

Figure 3. Mean change in heart rate to a 10-sec, nonsignal auditory stimulus presented either $30 \mathrm{sec}$ (open circles) or $15 \mathrm{~min}$ (closed circles) after the animals had been shocked (left panel). The right panel shows the mean change in heart rate to the same auditory stimulus in these two groups following a 15-min retention interval. than were the animals that received the tone $15 \mathrm{~min}$ after shock, this difference was not significant $\left(\chi^{2}=2.74, p<\right.$ .10). Presentation of the auditory stimulus did not reliably elicit the behavioral response in either group during the second test session.

Basal heart rate. Analysis of basal heart rates (obtained during the 5-sec prestimulus period) during the first session yielded a significant effect of group, trial, and a group $\times$ trial interaction [smallest $F(3,66)=4.94, p<.01$ ] These differences were due to a slight reduction in heart rate across the four trials in the animals tested $15 \mathrm{~min}$ after shock but not in those tested $30 \mathrm{sec}$ after shock. The two groups did not differ in baseline heart rate on Trial 1, where the largest difference in the heart rate orienting response was observed. Analysis of basal heart rates during the second session failed to yield any significant effects (largest $F=1.14, p>.10$ ). These data are presented in Table 2.

\section{Discussion}

Administration of several inescapable electric shocks shortly prior to presentation of a novel auditory stimulus markedly inhibited the occurrence of the cardiac orienting response, but did not have a statistically significant effect on the behavioral response. The same pattern of results following shock was also found in Experiment 1 of Saiers et al. (1990; but see Experiment 2 of that study).

Inhibition of the cardiac orienting response, however, had no apparent effect on habituation of this response. Neither group in this experiment displayed an orienting response to the same auditory stimulus when it was represented following a 15 -min retention interval. This result again demonstrates that habituation of the orienting response to a novel auditory stimulus can occur in the absence of a response to that stimulus.

\section{Experiment 1C}

In this experiment, a novel auditory stimulus was presented either $30 \mathrm{sec}$ or $15 \mathrm{~min}$ following a change in environmental context. The context change consisted of altering the olfactory, visual, and auditory characteristics of the test environment. This procedure is known to inhibit the orienting response to an auditory stimulus (Saiers et al., 1990). Fifteen minutes after the initial stimulus sequence, the same auditory stimulus was presented to determine what effect, if any, inhibition of the orienting response had on habituation of the orienting response.

\section{Method}

Two groups ( $n s=9$ ) of experimentally naive preweanling rats were used as subjects. All procedures were the same as in the preceding experiments except for the apparatus in which the animals were tested. In this experiment, the animals were placed in a Plexiglas cylinder (14 cm in diameter and $25 \mathrm{~cm}$ long) mounted horizontally in an IAC. A gentle airstream passing through the cylinder produced a sound similar to white noise and introduced an odor (amyl acetate) into the chamber. The IAC was illuminated by a $15-\mathrm{W}$ incandescent light as well as a 6-W red light. After $15 \mathrm{~min}$ in this environment, the airstream and the $15-\mathrm{W}$ incandescent light were 
turned off, resulting in a substantial change in the auditory, visual, and olfactory components of the environment. Animals in two separate groups were given four presentations of a novel auditory stimulus either $30 \mathrm{sec}$ or $15 \mathrm{~min}$ after this change in environmental context. Fifteen minutes after completion of the initial stimulus presentations, the same stimulus sequence was presented again to all animals.

In this experiment, no data on the behavioral response to the auditory stimulus could be obtained. The design of the apparatus, in conjunction with the very dim illumination in the test chamber (a $6 \mathrm{~W}$ red light), precluded reliable behavioral observations.

\section{Results}

Heart rate orienting response. Changing the environmental context $30 \mathrm{sec}$ prior to presenting a novel auditory stimulus markedly reduced the cardiac component of the orienting response to that stimulus. The animals tested 15 min after the context had been changed, however, exhibited a large cardiac response to the tone. These data are presented in the left panel of Figure 4. Analysis of the heart rate data for the first session yielded a significant effect of group, trial, and a group $\times$ trial interaction [smallest $F(3,48)=3.41, p<.05$ ]. The group $\times$ trial interaction was due to the significant effect of trial for the subjects tested 15 min after the context shift $[F(3,24)=7.41, p<.01]$ but not for the subjects tested $30 \mathrm{sec}$ after the context shift $(F<1.0)$.

Although shifting the environmental context was effective in inhibiting the orienting response to a novel auditory stimulus, it had no effect on habituation of the orienting response. When the same auditory stimulus was presented 15 min later, neither group of animals showed a cardiac orienting response. These data are presented in the right panel of Figure 4. Analysis of these data failed to indicate any significant effects [largest $F(1,16)=2.3$, $p>.10]$.

Basal heart rate. There were no significant differences in basal heart rate in either of the two stimulus presenta-

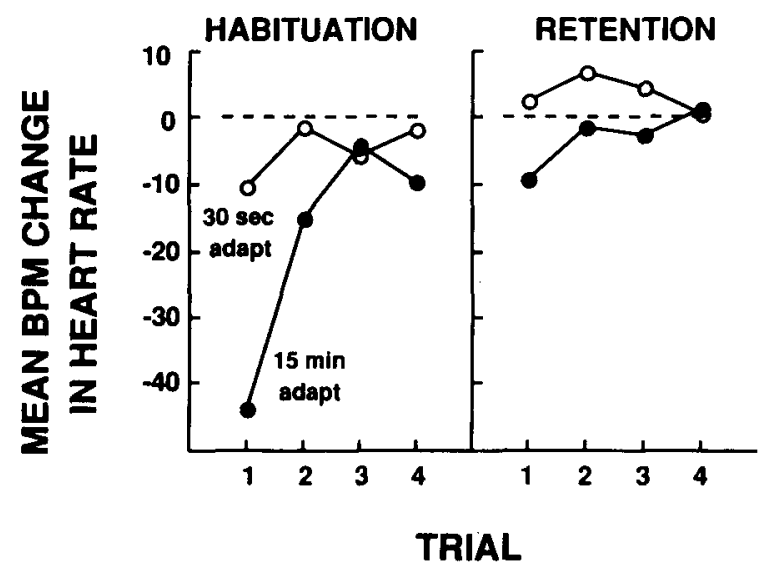

Figure 4. Mean change in heart rate to a 10-sec, nonsignal auditory stimulus presented either $30 \mathrm{sec}$ (open circles) or 15 min (closed circles) after a change in the environmental context (left panel). The right panel shows the mean change in heart rate to the same auditory stimulus in these two groups after a 15-min retention interval. tion sessions in this experiment [largest $F(3,48)=3.48$, $p>.10]$ These data are presented in Table 2 .

\section{Discussion}

Changing the visual, auditory, and olfactory characteristics of the environmental context shortly prior to the presentation of a novel auditory stimulus markedly reduced the cardiodeceleratory component of the orienting response to that stimulus. Moreover, as in the previous two experiments, inhibition of this autonomic component of the orienting response did not impair habituation of the orienting response as measured by retention of habituation following a 15-min retention interval. Retention of habituation in the absence of any initial reaction to the eliciting stimulus revealed that latent habituation had $\propto c$ curred.

\section{EXPERIMENT 2}

Although it has not been the focus of extensive research, most analysts of animal learning would probably agree that, given an equal number of trials, latent learning is likely to be less firmly established than conventional learning. This did not appear to be the case for the results obtained in the above experiments on latent habituation. No differences in retention of habituation were seen between the groups in which the orienting response was elicited and then habituated and the groups in which the orienting response was inhibited by one of the three experimental conditions. However, those tests were administered following only a 15-min retention interval, and it is possible that differences in retention of habituation between the two groups might have been obscured by a ceiling effect. If that were the case, differences between the two groups might emerge as habituation wanes with increasing retention intervals. Experiment 2 investigated this possibility.

Retention of habituation declines rapidly over a 24-h period in the preweanling rat (Richardson \& Campbell, 1991), making it an excellent subject to compare retention of habituation when the response is elicited and when it is not. In this experiment, preweanling rats were given the same four auditory stimulus presentations under conditions that either permitted or inhibited the orienting response and then were tested for retention of habituation $.25,1$, or $24 \mathrm{~h}$ later.

\section{Method}

Subjects. Sixty-six experimentally naive, 17-day-old preweanling rats were used as subjects.

Apparatus. The apparatus was the same as that used in Experiment $1 \mathrm{~A}$.

Procedure. All procedures were the same as in Experiment 1A except that the second series of stimulus presentations occurred either $0.25 \mathrm{~h}(n=20), 1 \mathrm{~h}(n=26)$, or $24 \mathrm{~h}(n=20)$ after the initial stimulus series. Half of the animals at all three intervals were given $30 \mathrm{sec}$ to adapt to the test environment prior to the initial stimulus presentation, whereas the other half were given $15 \mathrm{~min}$ to adapt. The animals tested after 1 or $24 \mathrm{~h}$ were returned to their home cages following the initial stimulus presentation session. The animals tested 


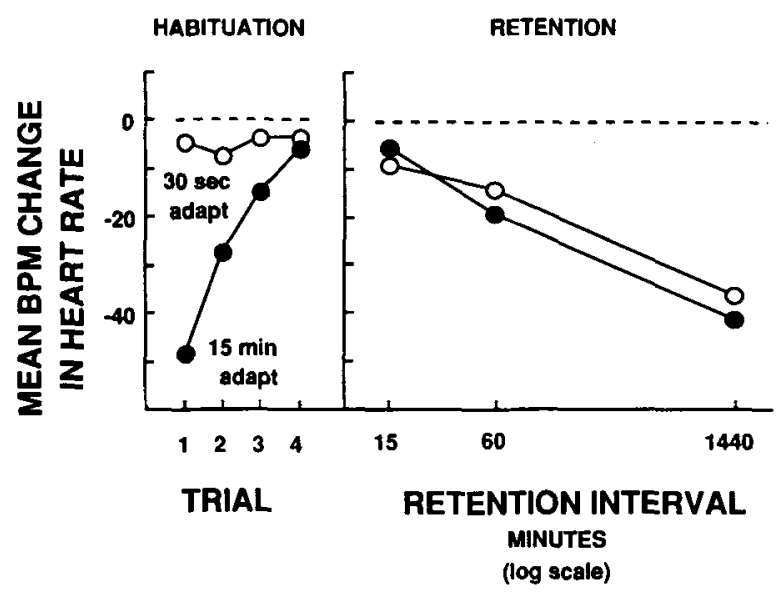

Figure 5. Mean change in heart rate to a 10 -sec, nonsignal auditory stimulus in the animals allowed to adapt to the test environment for either $30 \mathrm{sec}$ (open circles) or 15 min (closed circles) prior to the initial stimulus presentation (left panel). The right panel shows the mean change in heart rate to the auditory stimulus in these two groups after a 15-, 60-, or 1,440-min retention interval.

at these two intervals were returned to the test environment and allowed to adapt for $15 \mathrm{~min}$ before the second stimulus series was initiated.

\section{Results}

Heart rate orienting response. As in Experiment 1A, the animals allowed to adapt to the test environment for 15 min showed a marked decrease in heart rate to the auditory stimulus, whereas those given only $30 \mathrm{sec}$ to adapt did not. These data are presented in the left panel of Figure 5. Analysis of these data (collapsed across the three subsequently formed groups) yielded a significant effect of group, trial, and interaction of group $\times$ trial [smallest $F(3,192)=23.79, p<.01]$. The group $\times$ trial interaction was due to the significant effect of trial for the animals given $15 \mathrm{~min}$ to adapt to the test environment $[F(3,96)=37.07, p<.01]$ but not for those animals given only $30 \mathrm{sec}$ of adaptation to the test environment $(F<1.0)$.

The cardiac response to the first stimulus presentation of the second series is presented in the right panel of Figure 5 . When the eliciting stimulus was presented again after a 15-min retention interval, the animals in both groups failed to respond to it. As the interval separating the two stimulus sessions increased, a larger cardiac response was observed in both groups. After a 24-h interval, the cardiac response evoked by the eliciting stimulus was equivalent to that seen in naive animals of this age. An ANOVA of these data yielded a significant effect of retention interval $[F(2,60)=15.83, p<.01]$. The effect of group as well as the interaction of retention interval and group were both nonsignificant $\left(F_{\mathrm{s}}<1.0\right)$.

Behavioral orienting response. The percentage of animals exhibiting the head jerk response to the initial presentation of the auditory stimulus is presented in Table 3 .
As was the case in Experiment $1 \mathrm{~A}$, the animals allowed to adapt to the unfamiliar test environment for only $30 \mathrm{sec}$ prior to stimulus presentation were much less likely to exhibit a head jerk than were the animals in the 15-min condition $\left(\chi^{2}=45.69, p<.01\right)$. Furthermore, when a 15 -min interval separated the two stimulus sessions, the behavioral response was not elicited in either group. With a 24-h interval between stimulus presentation sessions, however, the animals in both groups exhibited the head jerk when the auditory stimulus was re-presented. The animals tested after the 1-hour interval performed intermediately to these two extremes. At no point, however, did the animals in the two groups differ in the likelihood of exhibiting the behavioral component of the orienting response.

Basal heart rate. Although there were no group differences in basal heart rate during the first exposure session (collapsed across the three subsequently formed groups; $F<1.0$ ), there was a significant effect of trial as well as a group $\times$ trial interaction [smallest $F(3,192)=$ $5.76, p<.01]$. The significant interaction was due to the increase in basal heart rate across trials for the animals in the 30-sec condition and the slight decrease in those animals in the 15-min condition. Pairwise comparisons with the Tukey test $(p<.05)$ showed that the animals in the 30-sec condition had significantly lower basal heart rates than did the animals in the 15-min condition on the first trial and significantly higher basal heart rates on the fourth trial. These data are presented in Table 4.

Basal heart rates prior to the first stimulus presentation of the second exposure session were also analyzed. This analysis yielded a significant effect of retention interval $[F(2,60)=4.66, p<.01]$. The effect of group $[F(1,60)=2.01, p=.10]$ and the group $\times$ retention interval interaction $(F<1.0)$ were not significant. The effect of retention interval was due to the slightly higher basal heart rates in the animals tested after the 24-h interval than those tested after the two shorter intervals. These data are also presented in Table 4.

Because of the large sample size in this experiment, it was possible to further explore the relation between basal heart rate and the cardiac component of the orienting response. The cardiac orienting response to the first stimulus presentation in the 15 animals in each condition with the lowest and highest basal heart rates is shown in Table 5 . Inspection of these data show that the significant group difference in basal heart rate was not responsible for the observed difference in the cardiac component of the orienting response. The animals with the lowest basal heart rates in the 15-min condition did not differ from the

Table 3

Percentage of Subjects Exhibiting a Head Jerk to the First Tone Presentation in Experiment 2

\begin{tabular}{ccrrr} 
& & \multicolumn{3}{c}{ Retention Interval-Hours } \\
\cline { 3 - 5 } Adaptation & Habituation & 0.25 & 1 & 24 \\
\hline $30 \mathrm{sec}$ & 0 & 0 & 23 & 80 \\
$15 \mathrm{~min}$ & 82 & 20 & 31 & 80 \\
\hline
\end{tabular}


Table 4

Basal Heart Rate (Beats per Minute) of Subjects in Experiment 2

\begin{tabular}{|c|c|c|c|c|c|c|c|}
\hline \multirow[b]{3}{*}{ Adaptation } & \multicolumn{4}{|c|}{ Habituation } & \multicolumn{3}{|c|}{ Retention } \\
\hline & \multicolumn{4}{|c|}{ Trial } & \multicolumn{3}{|c|}{ Retention Interval-Hours } \\
\hline & 1 & 2 & 3 & 4 & 0.25 & 1 & 24 \\
\hline $30 \mathrm{sec}$ & 468 & $\overline{489}$ & 501 & 513 & 518 & 500 & 534 \\
\hline $15 \mathrm{~min}$ & 520 & 491 & 499 & 493 & 493 & 498 & 523 \\
\hline
\end{tabular}

Table 5

The Cardiac Orienting Responses in Animals with the Lowest and Highest Basal Heart Rates (Beats per Minute) in Each Condition in Experiment 2, Habituation Trial 1

\begin{tabular}{cccccc}
\hline & \multicolumn{2}{c}{ Lowest 15} & & \multicolumn{2}{c}{ Highest 15} \\
\cline { 2 - 3 } \cline { 5 - 6 } Adaptation & Heart Rate & Orienting Response & & Heart Rate & Orienting Response \\
\hline $30 \mathrm{sec}$ & 432 & -3.77 & & 503 & -4.75 \\
$15 \mathrm{~min}$ & 499 & -43.45 & & 541 & -52.19 \\
\hline
\end{tabular}

animals with the highest basal heart rates in the 30 -sec condition $(F<1.0)$. However, these two groups were markedly different in terms of the cardiac deceleration to the first stimulus presentation $[F(1,28)=21.58, p<$ $.01]$. This confirms the conclusion, reached in several earlier studies, that basal heart rate typically has little influence on magnitude of the heart rate orienting response within this range of basal heart rates.

\section{Discussion}

The results of this experiment demonstrate that there are no substantive differences in retention of habituation and retention of latent habituation of the orienting response. The rate of forgetting (loss of habituation) was essentially identical in the two groups. These findings, in combination with those of the first three experiments, establish that elicitation of the orienting response is not necessary to produce habituation of that response to a novel stimulus.

\section{GENERAL DISCUSSION}

The present study unequivocally demonstrates latent habituation of the orienting response. One group of animals in each experiment (those in the 30 -sec condition) did not orient to a novel, nonsignal auditory stimulus when it was first presented, whereas another group (those in the 15-min condition) displayed a robust response, which habituated with repeated stimulus presentations. Despite these marked differences in initial response to the auditory stimulus, both groups displayed comparable levels of habituation when the same stimulus was presented following a brief retention interval. In Experiments 1A, 1B, and $1 \mathrm{C}$, the stimulus was re-presented after a 15 -min interval, the time it takes the disrupting effects of the unfamiliar environment, electric shock, and the shift in contextual cues to dissipate. At this short interval, the animals in both groups exhibited complete habituation of the orienting response. Retention of habituation was examined in Experiment 2. The forgetting function was the same for the two groups: perfect retention after $15 \mathrm{~min}$, complete forgetting after $24 \mathrm{~h}$, and an intermediate level of retention after $1 \mathrm{~h}$.

The failure of animals in the $30-\mathrm{sec}$ condition to respond to a previously presented stimulus that did not initially elicit a response constitutes latent habituation. This finding is contrary to the report of Wood (1988) on habituation in Stentor, a contractile protozoan. Wood found that habituation in this simple organism was dependent on $\alpha$ currence of the response. If the response was not elicited, repeated stimulation of the receptor was without effect, that is, no habituation occurred. In the present preparation, it appears that elicitation of the orienting response is not necessary for habituation to occur. Instead of being "response dependent" (see Wood, 1988), habituation of the orienting response is "response independent."

The demonstration of latent habituation of the orienting response is of considerable relevance to contemporary analyses of the role of this reaction in information processing. Although many different theories have been proposed concerning the functional significance of the orienting response for attention, they can be loosely classified into three groups (Jennings, 1986). Some investigators have proposed that the orienting response is merely an indicator of attention and that it has no effect on subsequent information processing. Others have suggested that the orienting response facilitates attention. Sokolov (1963), for example, maintained that the orienting response increased sensory analyzer sensitivity. Finally, some have proposed that the orienting response regulates attention. Stimuli that elicit an orienting response are attended to and processed; those that do not elicit the orienting response are not processed or encoded. Ohman (1979), for example, has proposed that "the OR is a prerequisite for learning"' (p. 445).

The results of the present study clearly demonstrate that animals can attend to and learn about an auditory stimulus even when they do not orient to that stimulus, either autonomically or behaviorally. To the extent that these are representative findings, they suggest that the orient- 
ing response does not regulate attention as proposed by Ohman (1979). If this response was necessary for the animals to learn about the auditory stimulus, then latent habituation would not have been observed in the animals in the $30-\mathrm{sec}$ condition. Furthermore, the results of this study suggest that elicitation of the orienting response does not facilitate attention since retention of habituation was not enhanced in the animals that oriented to the stimulus compared with those that did not. Finally, the finding that animals can attend to, and learn about, a stimulus without exhibiting an orienting response shows that this reaction does not always accurately indicate when animals are attending to a stimulus. Although the occurrence of the orienting response may indicate that an animal is attending to a stimulus, nonoccurrence of that response cannot be taken as evidence that the animal is not attending to the stimulus.

A recent study by Dawson, Filion, and Schell (1989) also questioned the relationship between the orienting response and attention. The specific hypothesis examined by Dawson et al. was that the orienting response is associated with the allocation of limited processing resources (e.g., Siddle \& Packer, 1987). Dawson et al. tested college students on a dual-task procedure. One task involved orienting to auditory stimuli presented to the "relevant" ear and ignoring stimuli presented to the other "irrelevant" ear. The second task involved speeded reactions to a brief light flash. Galvanic skin response was used as the index of the orienting response. Dawson et al. found that reaction time on the visual task was indeed slower after elicitation of the orienting response, suggesting that processing resources had been allocated to the auditory stimulus. However, Dawson et al. also reported that although relevant tones elicited the largest orienting response, irrelevant tones had the greatest effect on reaction time in the visual task. Because of this dissociation between magnitude of the orienting response and magnitude of disruption on the visual task, Dawson et al. concluded that "the relationship between autonomic orienting and resource allocation is a reliable but complex one in need of further research" (p. 571).

In the present study, a novel, nonsignal auditory stimulus did not elicit an orienting response when presented $30 \mathrm{sec}$ after the animal had been placed in an unfamiliar environment, shocked, or experienced a shift in the environmental context. Although this effect permitted demonstration of latent habituation, it is somewhat perplexing as to why the orienting response was inhibited under these conditions. As an involuntary, automatic reaction (e.g, Graham, 1992; Richards \& Casey, 1992), the orienting response might be expected to be highly resistant to disruption, especially under circumstances (such as an unfamiliar environment, painful stimulation, or a change in contextual cues) that might require adaptive defense or flight reactions. The results of the present study, however, provided no support for this expectation and clearly showed that the orienting response is rather easily dis- rupted by circumstances that might be expected to enhance attention to incoming sensory stimuli.

A recent series of studies by Carew and his colleagues also demonstrated inhibition of an unconditioned reaction to a sensory stimulus. Marcus, Nolen, Rankin, and Carew (1988), for example, found that the siphon-withdrawal response in adult Aplysia to tactile stimulation was markedly reduced in amplitude when animals were shocked $90 \mathrm{sec}$ prior to the tactile stimulus. The withdrawal response recovered to control levels $10 \mathrm{~min}$ after the shock. These findings have obvious conceptual and temporal similarities to the results of the present paper. In combination with the present results (see also Richardson et al., 1988, and Saiers et al., 1990), the recent work by Carew and his colleagues firmly establishes the generality of inhibition of unconditioned reactions to sensory stimuli. This effect is seen not only across species (rats and Aplysia), but also with different types of unconditioned responses (orienting and defensive responses). One major theoretical consequence of this effect, as noted by Marcus et al. (1988), will be the revision of dual-process models of nonassociative learning (Groves \& Thompson, 1970). New multiprocess models will have to be developed in order to account for the phenomenon of response inhibition (for additional discussion of multiprocess models of nonassociative learning, see Rankin \& Carew, 1989). Although there have been several reports of inhibition of the defensive response in Aplysia (e.g., Fitzgerald \& Carew, 1991; Mackey et al., 1987; Marcus et al., 1988), there have not been any studies, to our knowledge, on latent habituation with this preparation.

Previously, we suggested "information overload" as one possible explanation for why the orienting response did not occur to a novel auditory stimulus presented $30 \mathrm{sec}$ after animals had been placed in an unfamiliar environment (Richardson et al., 1988). According to this hypothesis, information inherent in the unfamiliar environment completely engages all of the animal's limited processing capacity, and the nominal stimulus is not even detected. As the animal adapts to the environment, some of these limited resources become available to process other information (like the nominal stimulus). Saiers et al. (1990) suggested that administration of shock or changing the environmental context reinitiates this process. The present study, however, provides no support for this proposition. Even though animals in the 30-sec condition did not show an orienting response to the auditory stimulus, they certainly detected, attended to, and learned about the stimulus.

Berntson, Boysen, and Cacioppo (1992) recently suggested another possible explanation for inhibition of the orienting response. Stimulus-induced changes in heart rate are the result of alterations in the autonomic nervous system. Typically, decreases in heart rate (e.g., orienting responses) are attributed to activation of the parasympathetic nervous system and increases in heart rate (e.g., defensive responses) are attributed to activation of the sym- 
pathetic nervous system. As noted by Berntson et al., however, in some situations stimuli may simultaneously activate both components of the autonomic nervous system. In such cases, the resulting cardiac response is the sum of these phasic changes in autonomic nervous system activity (e.g., Quigley \& Berntson, 1990). To explain our results, Berntson et al. (1992, p. 195) suggested that inhibition of the orienting response could be due to "greater conjoint parasympathetic and sympathetic activation (i.e., co-activation)" when the stimulus is presented $30 \mathrm{sec}$ after placement in an unfamiliar environment, shock, or a shift in environmental context than when it is presented $15 \mathrm{~min}$ after these treatments. The underlying assumption is that "novel or challenging environmentsenvironments in which optimal or adaptive behavioral responses are unclear-may be more likely to evoke and/or promote coactivation of both the sympathetic and parasympathetic divisions than are familiar environments" (Berntson, Cacioppo, \& Quigley, 1991, p. 483).

Although this analysis may be an accurate description of the autonomic interactions underlying the present findings, it is not clear how the behavioral results obtained in this research (see also Richardson et al., 1988; Saiers et al., 1990) could be incorporated into this model since the relationship between stimulus-induced coactivation of the autonomic nervous system and behavior has not been delineated. What is clear from the present data is that a behavioral orienting response to an auditory stimulus can habituate even when that response is not elicited during the initial stimulus series.

In summary, the results of the present study demonstrate (1) that the cardiac and behavioral components of the orienting response to a novel, nonsignal auditory stimulus are easily inhibited and (2) that this inhibition of the orienting response does not affect information processing. These results are contrary to current theoretical conceptualizations of the orienting response that view this reaction as an automatic, reflexive response intrinsically related to attention and information processing. In addition, these results suggest that future models of nonassociative learning should include an analysis of both response inhibition and latent habituation.

\section{REFERENCES}

Berntson, G. G., Boysen, S. T., \& Cacioppo, J. T. (1992). Cardiac orienting and defensive responses: Potential origins in autonomic space. In B. A. Campbell, H. Hayne, \& R. Richardson (Eds.), Attention and information processing in infants and adults: Perspectives from human and animal research (pp. 163-200). Hillsdale, NJ: Erlbaum.

Berntson, G. G., CACIOPPO, J. T., \&uigley, K. S. (1991). Autonomic determinism: The modes of autonomic control, the doctrine of autonomic space, and the laws of autonomic constraint. Psychological Review, 98, 459-487.

BoRNSTEIN, M. (1985). Habituation of attention as a measure of visual information processing in human infants: Summary, systematization, and synthesis. In G. Gottlieb \& N. Krasnegor (Eds.), Measurement of audition and vision in the first year of postmatal life (pp. 253-300). Norwood, NJ: Ablex.
Campbell, B. A., Hayne, H., Richardson, R. (Eds.). (1992). Attention and information processing in infants and adults: Perspectives from human and animal research. Hillsdale, NJ: Erlbaum.

CAREW, T. J. (1984). An introduction to cellular approaches used in the analysis of habituation and sensitization in Aplysia. In H. V. S. Peeke \& L. Petrinovich (Eds.), Habituation, sensitization, and behavior (pp. 205-249). Orlando, FL: Academic Press.

Сhamizo, V. D., Mackintosh, N. J. (1989). Latent learning and latent inhibition in maze discriminations. Quanerly Joumal of Experimental Psychology, 41B, 21-31.

Dawson, M. E., Filion, D. L., \& Schell, A. M. (1989). Is elicitation of the autonomic orienting response associated with allocation of processing resources? Psychophysiology, 26, 560-572.

Fitzgerald, K., C CAREw, T. J. (1991). Serotonin mimics tail shock in producing transient inhibition in the siphon withdrawal reflex of Aplysia. Journal of Neuroscience, 11, 2510-2518.

Graham, F. K. (1979). Distinguishing among orienting, defense, and startle reflexes. In H. D. Kimmel, E. H. van Olst, \& J. F. Orlebeke (Eds.), The orienting reflex in humans (pp. 137-166). Hillsdale, NJ: Erlbaum.

Graham, F. K. (1992). Attention: The heartbeat, the blink, and the brain. In B. A. Campbell, H. Hayne, \& R. Richardson (Eds.), Attention and information processing in infants and adults: Perspectives from human and animal research (pp. 3-29). Hillsdale, NJ: Erlbaum.

Groves, P. M., \& Thompson, R. F. (1970). Habituation: A dual-process theory. Psychological Review, 77, 419-450.

JENNINGS, J. R. (1986). Bodily changes during attending. In M. G. H. Coles, E. Donchin, \& S. W. Porges (Eds.), Psychophysiology: Systems, processes, and applications (pp. 268-289). New York: Guilford.

Mackey, S. L., Glanzman, D. L., Small, S. A., Dyke, A. M., KanDEL, E. R., Hawkins, R. D. (1987). Aversive stimuli produce inhibition as well as sensitization of the siphon withdrawal reflex of Aplysia: A possible behavioral role for presynaptic inhibition mediated by the peptide FMRFamide. Proceedings of the National Academy of Sciences, USA, 84, 8730-8734.

Marcus, E. A., Nolen, T. G., Rankin, C. H., Carew, T. J. (1988). Behavioral dissociation of dishabituation, sensitization, and inhibition in Aplysia. Science, 241, 210-213.

Ohman, A. (1979). The orienting response, attention, and learning: An information-processing perspective. In H. D. Kimmel, E. H. van Olst, \& J. F. Orlebeke (Eds.), The orienting reflex in humans (pp. 443471). Hillsdale, NJ: Erlbaum.

Quigley, K. S., Berntson, G. G. (1990). Autonomic origins of cardiac responses to non-signal stimuli in the rat. Behavioral Neuroscience, 104, 752-762.

Rankin, C. H., CAREW, T. J. (1989). Developmental analysis in Aplysia reveals inhibitory as well as facilitory effects of tail shock. Behavioral Neuroscience, 103, 334-344.

Richards, J. E., \& CASEY, B. J. (1992). Development of sustained visual attention in the human infant. In B. A. Campbell, H. Hayne, \& R. Richardson (Eds.), Attention and information processing in infants and adults: Perspectives from human and animal research (pp. 3060). Hillsdale, NJ: Erlbaum.

Richardson, R., Campbell, B. A. (1991). Ontogeny of long-term, nonassociative memory in the rat. Animal Leaming \& Behavior, 19. 1-10.

Richardson, R., Hayne, H., \& Campbell, B. A. (1992a). The orienting response as a measure of attention and information processing in the developing rat. In B. A. Campbell, H. Hayne, \& R. Richardson (Eds.), Attention and information processing in infants and adults: Perspectives from human and animal research (pp. 113-136). Hillsdale, NJ: Erlbaum.

Richardson, R., Hayne, H., Campbell, B. A. (1992b). Responseindependent habituation of the orienting response in the preweanling rat. Animal Learning \& Behavior, 20, 17-24.

Richardson, R., Siegel, M. A., CAmpbell, B. A. (1988). Unfamiliar environments impair information processing as measured by behavioral and cardiac orienting responses to auditory stimuli in preweanling and adult rats. Developmental Psychobiology, 21, $491-503$. 
RICHARDSON, R., \& WANG, P. (1992). (Inter-rater reliability in-scoring the behavioral component of the orienting response to an auditory stimulus). Unpublished raw data.

Saiers, J. A., Richardson, R., \& Campbell, B. A. (1990). Disruption and recovery of the orienting response following shock or context change in preweanling rats. Psychophysiology, 27, 45-56.

Siddle, D. A. T., \& PACker, J. S. (1987). Stimulus omission and dishabituation of the electrodermal orienting response: The allocation of processing resources. Psychophysiology, 24, 181-190.

Siegel, M. A., Sananes, C. B., Gaddy, J. R., \& Campbell, B. A. (1987). Dissociation of heart rate and somatomotor orienting responses to novel stimuli in preweanling rats. Psychobiology, 15, 122-127.
Sokolov, E. N. (1963). Perception and the conditioned reflex. New York: Macmillan.

Tolman, E. C. (1932). Purposive behavior in animals and men. New York: Appleton-Century-Crofts.

TURPIN, G. (1983). Unconditioned reflexes and the autonomic nervous system. In D. Siddle (Ed.), Orienting and habituation: Perspectives in human research (pp. 1-70). New York: Wiley.

WooD, D. C. (1988). Habituation in Stentor: A response-dependent process. Journal of Neuroscience, 8, 2248-2253.

(Manuscript received September 9, 1991; revision accepted for publication April 9, 1992.) 